JAMP: Jurnal Adminitrasi dan Manajemen Pendidikan

Volume 2 Nomor 4 Desember 2019, Hal : 188-193

Tersedia Online di http://journal2.um.ac.id/index.php/jamp/

ISSN 2615-8574 (online)

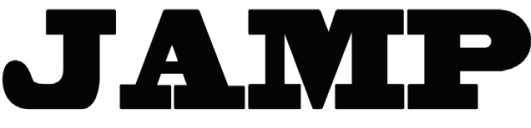

JURNAL ADMINISTRASI DAN MANAJEMEN PENDIDIKAN

\title{
PERPUSTAKAAN SEBAGAI PUSAT SUMBER BELAJAR UNTUK MEWUJUDKAN SEKOLAH YANG UNGGUL
}

\author{
Bella Sonia Rohmadhani \\ H. A. Yusuf Sobri \\ Imam Gunawan \\ Universitas Negeri Malang, Jl. Semarang 5 Malang 65145
bellasoniaa12@gmail.com
}

\begin{abstract}
The purpose of this study is to explain: (1) the application of library functions; (2) library services as a center for learning resources; (3) explain the effort to realize superior schools through library services. This research uses qualitative research with research on the types of research that describe and analyze libraries in schools. Data obtained through interviews with several informants consisting of the head of the library, librarians, teachers and students and the head of SMK 4 Malang. The key informant in this study was the head of the library at SMK 4 Malang namely Mr. Mokhamad Rukhan. Checking data in this study uses credibility techniques. By means of research perseverance, triangulation, extension of observation time, and adequacy of reference materials. The conclusions of this study are: (1) schools that implement educational, informative, recreational, research or research functions, and administrative responsibilities; (2) school library services carry out the functions of system development, media services, production, administration, and training. The impact generated by the change and development is an advantage, namely about comfort, the place of facilities, the location of the library location
\end{abstract}

Keyword: library, learning resources, superior schools

\begin{abstract}
Abstrak: Tujuan penelitian ini untuk menjelaskan: (1) penerapan fungsi perpustakaan; (2) layanan perpustakaan sebagai pusat sumber belajar; (3) menjelaskan upaya mewujudkan sekolah unggul melalui pelayanan perpustakaan. Penelitian ini menggunakan pendekatan kualitatif dengan jenis penelitian studi kasus karena mendeskripsikan dan menganalisis secara mendalam tentang perpustakaan di sekolah. Data diperoleh melalui wawancara dengan beberapa informan yang terdiri dari kepala perpustakaan, pustakawan, guru dan siswa dan kepala SMKN 4 Malang. Informan kunci dalam penelitian ini adalah kepala perpustakaan SMKN 4 Malang yaitu Bapak Mokhamad Rukhan. Pengecekan data dalam penelitian ini menggunakan teknik kredibilitas. Dengan cara ketekunan penelitian, triangulasi, perpanjangan waktu pengamatan, dan kecukupan bahan referensi. Simpulan penelitian ini yaitu: (1) sekolah menerapkan fungsi edukatif, informatif, rekreatif, riset atau penelitian, dan tanggungjawab administratif; (2) layanan perpustakaan sekolah menerapkan fungsi pengembangan sistem instruksional, pelayanan media, produksi, administrasi, dan pelatihan. Dampak yang dihasilkan oleh adanya perubahan dan pengembangan tersebut adalah kelebihan yaitu tentang kenyamanan, tempat sarananya, letak lokasi perpustakaan

Kata Kunci: perpustakaan, sumber belajar, sekolah unggul
\end{abstract}

Perpustakaan mempunyai peran yang signifikan untuk meningkatkan literasi informasi, minat baca dan juga mengembangkan pengetahuan. Adanya perpustakaan sekolah, peserta didik dapat memanfaatkan fasilitas perpustakaan dengan mengembangkan ilmu dan juga melakukan kegiatan belajar secara mandiri atau secara berkelompok. Dalam perkembangannya fungsi perpustakaan ini telah dipadukan 
dalam suatu unit kerja, yaitu apa yang disebut pusat sumber belajar (PSB). Begitu pentingnya peranan pusat sumber belajar ini sesuai dengan pendapat Mudhoffir (2001:vii) mengatakan bahwa pusat sumber belajar khususnya untuk menunjang keberhasilan belajar, baik untuk mahasiswa maupun untuk siswa sekolah lanjutan.

Perpustakaan sekolah adalah suatu kumpulan/unit kerja yang berisi kumpulan koleksi pustaka, baik buku-buku maupun bukan buku (non book material) yang diorganisasi secara sistematis dalam suatu ruang yang dapat membantu murid-murid dan guru-guru dalam proses belajar mengajar di sekolah. Menurut Yusuf dan Suhendar (2010) mengungkapkan secara lebih lengkap dan detail bahwa fungsi umum perpustakaan sekolah meliputi edukatif, informatif, rekreasi, dan riset atau penelitian sederhana. Bafadal (2009) menambahkan satu fungsi lagi, yaitu tanggung jawab administratif. Beberapa fungsi perpustakaan sekolah menurut Bafadal (2009:6) sebagai berikut: (1) Fungsi Edukatif, bermakna bahwa perpustakaan sekolah diharapkan dapat membiasakan peserta didik elajar secara mandiri tanpa bimbingan guru, baik secara individual maupun kelompok.

Keberadaan perpustakaan sebagai pusat sumber belajar merupakan salah satu langkah yang ditempuh sekolah untuk membangun sekolah yang unggul. Sekolah unggul merupakan lembaga pendidikan yang lahir dari sebuah keinginan untuk memiliki sekolah yang mampu berprestasi di tingkat nasional dan internasional dalam penguasaan ilmu pengetahuan dan teknologi oleh ditunjang oleh akhlakul karimah. Bafadal (2003) menyatakan bahwa untuk mencapai kriteria sekolah unggul dituntut adanya tenaga, fasilitas, dan dana yang memadai dan tidak semua sekolah dapat memenuhinya. Secara teknis, pengembangan sekolah unggul menuntut adanya tenaga yang profesional dan fasilitas yang memadai.

Penelitian terdahulu yang dilakukan oleh Fatkhulia Ayu Rinenty dengan judul pemanfaatan perpustakaan sebagai sumber belajar di Madrasah Ibtidaiyah Ma'arif Giriloyo 1 Wukirsari, mendapatkan hasil penelitian yang menyatakan bahwa pemanfaatan perpustakaan sebagai sumber belajar dilakukan dengan cara pemanfaatan koleksi dan pemanfaatan sarana. Pemanfaatan koleksi yang banyak digunakan berupa koleksi berupa referensi buku terutama koleksi referensi buku fiksi, sedangkan pemanfataan sarana dilakukan dengan menggunakan sarana ruangan perpustakaan untuk kegiatan belajar mengajar. Dengan demikian peran perpustakaan dalam dunia pendidikan utamanya dalam meningkatkan mutu pendidikan dan ilmu pengetahuan mutlak dibutuhkan. Berdasarkan penelitian sebelumnya peneliti mengembangkan dengan mengangkat judul yang serupa tetapi memiliki perbedaan. Peneliti membahas tentang perpustakaan sebagai pusat sumber belajar sebagai upaya untuk mewujudkan sekolah yang unggul di SMK Negeri 4 Malang.

Tujuan penelitian ini untuk menjelaskan: (1) penerapan fungsi perpustakaan; (2) layanan perpustakaan sebagai pusat sumber belajar; (3) menjelaskan upaya mewujudkan sekolah unggul melalui pelayanan perpustakaan.

\section{METODE}

Rancangan penelitian ini menggunakan pendekatan kualitatif dengan jenis penelitian studi kasus. Studi kasus dipilih dengan alasan yaitu karena mendeskripsikan dan menganalisis secara mendalam tentang perpustakaan di sekolah. Dalam penelitian ini peneliti melakukan beberapa teknik dalam pengumpulan data untuk mencapai tujuan peneliian yang dilakukan. Ada tiga teknik yang digunakan yakni wawancara, observasi, dan dokumentasi. Data diperoleh melalui wawancara dengan beberapa informan yang terdiri dari kepala perpustakaan, pustakawan, guru dan siswa dan kepala SMKN 4 Malang. Informan kunci dalam penelitian ini adalah kepala perpustakaan SMKN 4 Malang yaitu Bapak Mokhamad Rukhan.

Teknik analisis data penelitian yang digunakan adalah fenomenologi. Dengan analisis dan representasi data yang terdiri dari pengolahan data, membaca dan mengingat data, menggambarkan data, mengklasifikasi data, interpretasi data, dan representasi dan visualisasi data. Pengecekan data dalam penelitian ini menggunakan teknik kredibilitas, yaitu dengan cara ketekunan pengamatan, triangulasi, perpanjangan waktu pengamatan, dan kecukupan referensi. 
Adapun tahap-tahap dalam penelitian ini adalah: 1) tahap persiapan, meliputi penyusunan rancangan penelitian dengan menentukan konteks penelitian, tujuan penelitian, pemilihan yang menjadi informan, teknik dalam pengumpulan data, menentukan lokasi, kemudian mengurus surat perijinan untuk melakukan studi pendahuluan, mempersiapkan pedoman wawancara, dan mempersiapkan alat yang dipergunakan (HP, buku catatan, bolpoin). 2) tahap pelaksanaan, peneliti mengumpulkan data dengan teknik observasi, wawancara, dan dokumentasi. 3) tahap pelaporan, tahap ini merupakan tahap terakhir dari sebuah penelitian

\section{HASIL}

\section{Penerapan Fungsi Perpustakaan}

Berdasarkan hasil analisis dokumen dan wawancara yang dilakukan peneliti, ada beberapa gambaran mengenai layanan perpustakaan berdasarkan fungsi perpustakaan, berdasarkan fungsi perpustakaan,yaitu: 1) fungsi edukatif, segala fasilitas dan sarana yang ada pada perpustakaan sekolah terutama koleksi yang dikelolanya banyak membantu para siswa dan guru untuk belajar dan memperoleh pengetahuan. 2) fungsi informatif, mengupayakan untuk peningkatan penyediaan koleksi perpustakaan baik berupa book atau non book yang bersifat memberikan informasi. 3) fungsi rekreasi sebagai pelengkap perpustakaan agar pengguna yang berada di perpustakaan merasa terhibur dan nyaman dengan adanya fasilitas tambahan. 4) fungsi riset dan penelitian, koleksi perpustakaan sekolah yang dimiliki dapat dijadikan bahan referensi untuk membantu dilakukannya kegiatan penelitian sederhana. 5) fungsi tanggung jawab administratiF, menerapkan standar operasional prosedur yang diberlakukan untuk pengunjung perpustakaan yaitu tentang sistem pelayanan peminjaman dan pengembalian buku

Unsur elemen yang terdapat dalam perpustakaan SMK Negeri 4 Malang yaitu pustakawan, pengguna (user), pustaka dan gedung perpustakaan. Selanjutnya peran perpustakaan yaitu: 1) pusat informasi, yang mempunyai beragam sumber informasi yaitu buku, majalah, dan media cetak lainnya.2) pusat inovasi, perpustakaan SMK Negeri 4 Malang menyediakan berbagai macam media yang diperlukan untuk siswa yang akan mengerjakan tugas. Selain itu, hasil karya guru maupun siswa juga dipublikasikan di perpustakaan.3) pusat sumber belajar, pengguna dapat mencari sumber pengetahuan atau informasi di perpustakaan, selain itu dapat pula menjadi sarana belajar mengajar di dalam perpustakaan.

\section{Layanan Perpustakaan Sebagai Pusat Sumber Belajar}

Perpustakaan SMK Negeri 4 Malang sebagai pusat sumber belajar memiliki lima fungsi yaitu: 1) fungsi pengembangan sistem instruksional menerapkan SOP yang diberlakukan bagi pengguna (user) untuk menggunakan layanan perpustakaan, serta perpustakaan melakukan seleksi peralatan dan bahan belajar. 2) fungsi pelayanan media, selain melayani peminjaman buku, perpustakaan SMK Negeri 4 Malang memiliki beberapa sarana seperti ruang komputer, ruang multimedia (3D) yang digunakan untuk keperluan siswa. 3) fungsi produksi, penerbitan buku yang diproduksi oleh perpustakan yang diperuntukkan bagi jurusan di SMK Negeri 4 Malang. 4) fungsi administrasi, melakukan pencatatan inventarisasi peralatan yang ada di perpustakaan SMK Negeri 4 Malang. 5) fungsi pelatihan, perpustakaan SMK Negeri 4 Malang sering mengadakan workshop dan pelatihan pengelolaan perpustakaan dan kepenulisan perpustakaan bagi pustakawan yang diadakan setiap tahun sebanyak 2-3 kali.

Langkah-langkah pengembangan Mmnjadi pusat sumber belajar yaitu: 1) berorientasi pada siswa, memberikan pelayanan kepada peserta didik. 2) desentralisasi, penempatan sarana dan fasilitas yang dapat digunakan pengguna. 3) fungsi produksi, buku di produksi sendiri untuk jurusan yang membutuhkan. 4) program dikembangkan secara terintergrasi dalam proses instruksional, seperi pemberlakuan SOP dan pelatihan untuk pustakawan.

Prinsip Pengembangan: 1) mencapai tujuan pembelajaran. 2) memberikan kemudahan bagi peserta didik. Dengan didukung oleh strategi pengembangan yaitu: 1) mengembangkan sarana dan fasilitas, selalu meningkatkan dan merawat sarana dan fasilitas yang ada di perpustakaan SMK Negeri 4 Malang. 2) mengembangkan program-program yang akan direncanakan, melakukan pelatihan bagi pustakawan dan mengadakan program yang diikuti oleh kader perpustakaan yaitu peserta didik SMK Negeri 4 Malang. 


\section{Upaya Mewujudkan Sekolah Unggul Melalui Pelayanan Perpustakaan}

Kriteria mewujudkan sekolah unggul melalui pelayanan perpustakaan antara lain: 1) adanya komponen perpustakaan yaitu adanya gedung, koleksi bahan pustaka, perlengkapan dan perabot dan tenaga kerja yang meliputi kepala perpustakaan dan pustakawan, peran pustakawan adalah melayani dan membantu pengguna perpustakaan. Melayani dalam proses peminjaman dan pengembalian buku, membersihkan buku, menata buku, mensortir buku yang sudah rusak dan yang masih bagus. 2) sarana dan prasarana, sarana meliputi gedung dan ruangan yang memadai dan cukup untuk menampung koleksi bahan pustaka, layanan, kegiatan pengolahan bahan pustaka, dan kegiatan administrasi. Lalu perabot, dan peralatan seperti rak, meja baca, kursi, lemari penyimpanan bahan pustaka, dan lemari katalog.

Prasarana: ruang baca, ruang karya seni, ruang diskusi, ruang 3D, ruang koleksi, ruang sirkulasi, ruang kerja petugas; 1) lingkungan belajar yang kondusif. Perpustakaan terletak strategis di tengah sekolah yang berdekatan dengan masjid sekolah; 2) peran perpustakaan adalah sebagai sarana sumber belajar; 3) perencanaan program, mengoptimalkan prasarana dan meningkatkan fasilitas yang ada. 4) strategi pengembangan, menambah inovasi dan menambah jumlah koleksi dari buku yang ada di perputakaan. 5) dampak yang dihasilkan yaitu kelebihan dan kekurangan dari perpustakaan SMK Negeri 4 Malang.

\section{PEMBAHASAN}

\section{Pengembangan Fungsi Perpustakaan}

Hasil temuan menunjukkan bahwa perpustakaan SMK Negeri 4 Malang menerapkan kelima fungsi yaitu: 1) fungsi edukatif, fasilitas dan sarana yang ada pada perpustakaan sekolah terutama koleksi buku yang dikelola banyak membantu para siswa dan guru untuk belajar dan memperoleh pengetahuan; 2) fungsi informatif, perpustakaan SMK Negeri 4 Malang mengupayakan penyediaan koleksi perpustakaan yang bersifat memberikan informasi mengenai hal-hal yang berhubungan dengan kepentingan pengguna; 3) fungsi rekreasi, adanya fasilitas yang bertujuan untuk menghibur penggunanya seperti ruang baca yang menarik, area audio visual 3 dimensi, ruang diskusi, ruang hasil karya siswa; 4) fungsi riset dan penelitian, dengan adanya koleksi yang ada di perpustakaan SMK Negeri 4 Malang ini dapat dijadikan bahan untuk membantu dilakukannya kegiatan penelitian sederhana; 5) fungsi tanggung jawab administratif, perpustakaan SMK Negeri 4 Malang menerapkan fungsi tanggung jawab administratif dengan memberlakukan Standar Operasional Prosedur (SOP) .

Hal ini sesuai dengan Bafadal (2009) bahwa perpustakaan mempunyai 5 fungsi: a) fungsi edukatif, dapat membiasakan peserta didik belajar secara mandiri tanpa bimbingan guru, baik secara individual maupun kelompok; b) fungsi informatif, perpustakaan yang sudah maju tidak hanya menyediakan bahan-bahan pustaka. Semua ini akan memberikan informasi atau keterangan yang diperlukan oleh peserta didik; c) fungsi rekreasi diharapkan dapat menghibur pembacanya di saat yang memungkinkan atau dengan kata lain sebagai pusat rekreasi. d) fungsi riset atau penelitian, dengan adanya perpustakaan yang lengkap fasilitasnya, peserta didik dan guru dapat melakukan riset, yaitu mengumpulkan data atau keterangan-keterangan yang dibutuhkan; e) Fungsi Tanggung Jawab Administratif, fungsi ini tampak dalam kegiatan sehari-hari di perpustakaan sekolah.

\section{Layanan Perpustakaan Sebagai Pusat Sumber Belajar}

Berdasarkan penelitian ditemukan bahwa perpustakaan SMK Negeri 4 Malang sebagai pusat sumber belajar yang dipaparkan berdasarkan fungsi yaitu: a) fungsi pengembangan sistem instruksional, pelaksanaanya menerapkan SOP yang diberlakukan bagi pengguna (user) untuk menggunakan layanan perpustakaan, serta perpustakaan melakukan seleksi peralatan dan bahan belajar; b) fungsi pelayanan media, memiliki beberapa sarana seperti ruang komputer, ruang multimedia 3 Dimensi yang digunakan untuk keperluan siswa; c) fungsi produksi, menerbitkan buku yang diproduksi oleh perpustakan yang diperuntukkan bagi jurusan di SMK Negeri 4 Malang; d) fungsi administrasi, melakukan pencatatan inventarisasi peralatan yang ada di perpustakaan; dan e) fungsi pelatihan, sering mengadakan workshop 
dan pelatihan pengelolaan perpustakaan dan kepenulisan bagi pustakawan yang diadakan setiap tahun sebanyak 2-3 kali.

Fungsi pelatihan ini bertujuan sesuai dengan yang dinyatakan oleh Haryanto (2013) menerangkan bahwa ketidakahlian seorang guru pustakawan dapat menjadi penghambat dalam kinerjanya. Agar keahlian tersebut meningkat, diperlukan pendidikan baik dalam bidang perpustakaan dan bidang lain yang berkaitan untuk dapat melahirkan guru pustakawan yang lebih produktif dalam berkinerja.

\section{Upaya Mewujudkan Sekolah Unggul Melalui Layanan Perpustakaan}

Sekolah unggul perlu ditunjang berbagai aspek salah satunya melalui perpustakaan. Hal ini juga diungkapkan oleh Bafadal (2003) bahwa untuk mencapai sekolah yang unggul dituntut adanya tenaga, fasilitas, dan dana yang memadai dan tidak semua sekolah dapat memenuhinya. SMK Negeri 4 Malang memiliki fasilitas perpustakaan yang mengikuti standar nasional perpustakaan. Perpustakaan SMK Negeri 4 Malang merupakan salah satu prasarana sekolah yang menunjang proses pembelajaran.

Kelebihan perpustakaan SMK Negeri 4 Malan diungkapkan oleh kepala perpustakaan dan kepala SMK Negeri 4 Malang: 1) kenyamanannya; 2) tempat sarananya; 3) lokasi; 4) sertifikat juara; 5) sudah terakreditasi. Sedangkan kekurangnnya adalah koleksi buku yang belum lengkap, berdasarkan temuan peneliti, koleksi yang belum terpenuhi adalah koleksi sastra. Mengenai ketentuan jumlah koleksi perpustakaan, dapat mengacu pada pendapat Suherman (2009:75) yang mengatakan bahwa tidak akan ada koleksi perpustakaan yang lengkap, yang ada adalah koleksi berdasarkan pada kebutuhan. Maka solusi untuk mengatasi kekurangan ialah dengan terus mengembangkan strategi yaitu menambah inovasi dan menambah koleksi buku.

\section{SIMPULAN}

Berdasarkan hasil penelitian dan pembahasan mengenai persepsi mahasiswa terhadap tingkat penguasaan kompetensi profesional dosen maka dapat disimpulkan: 1) sekolah menerapkan fungsi edukatif, informatif, rekreatif, riset atau penelitian, dan tanggung jawab administratif; 2) layanan perpustakaan sekolah menerapkan fungsi pengembangan sistem instruksional, pelayanan media, produksi, administrasi, dan pelatihan. Dampak yang dihasilkan oleh adanya perubahan dan pengembangan tersebut adalah kelebihan yaitu tentang kenyamanan, tempat sarananya, letak lokasi perpustakaan. 3) kriteria mewujudkan sekolah unggul melalui pelayanan perpustakaan antara lain: a) adanya komponen perpustakaan dan sarana dan prasarana yang menunjang.

\section{SARAN}

Kepala sekolah SMK Negeri 4 Malang untuk lebih memperhatikan perpustakaan dengan mengawasi dan mengevaluasi berbagai kekurangan perpustakaan terutama yang berkaitan dengan pengadaan fasilitas yang dibutuhkan oleh pengguna perpustakaan. Demi peningkatan yang lebih baik lagi jika perlu pihak perpustakaan dapat menyebarkan angket kepada para pengunjung untuk mengetahui apa yang diinginkan oleh para pengguna, dan bekerjasama dengan warga sekolah baik itu guru, kepala sekolah, dan siswa. Selalu mengadakan program-program yang menarik siswa seperti pameran atau perlombaan agar siswa tertarik untuk mengunjungi perpustakaan.

\section{DAFTAR RUJUKAN}

Bafadal, I. 2003. Manajemen Peningkatan Mutu Sekolah Dasar: dari Sentralisasi Menuju Desentralisasi. Jakarta: Bumi Aksara.

Bafadal, I. 2009. Pengelolaan Perspustakaan Sekolah. Jakarta: Bumi Aksara.

Febriani, R. 2014. Pemanfaatan Perpustakaan Sekolah Sebagai Sumber Belajar Siswa, (Online), ( http: //jurnal. unt an.ac.id/index.ph p/jpdpb/article/view/4709/4762), diakses 25 Mei 2019 
Haryanto, S. 2013. Implementasi Standarisasi Kepustakawanan Menuju Akreditasi dan Penguatan Citra Pustakawan. Buletin Sangkakala, 15, 14-18.

Mudhoffir. 2001. Prinsip-Prinsip Pengelolaan Pusat Sumber belajar. Bandung: Remaja Rosda Karya.

Suherman. 2009. Perpustakan sebagai Jantung Sekolah. Bandung: MQS Publishing.

Yusuf, P., dan Suhendar, Y. 2010. Pedoman Penyelenggaraan Perpustakaan Sekolah. Jakarta: Kencana Predana Media Group. 